\title{
A teatralidade das artes
}

\author{
Ana Pais
}

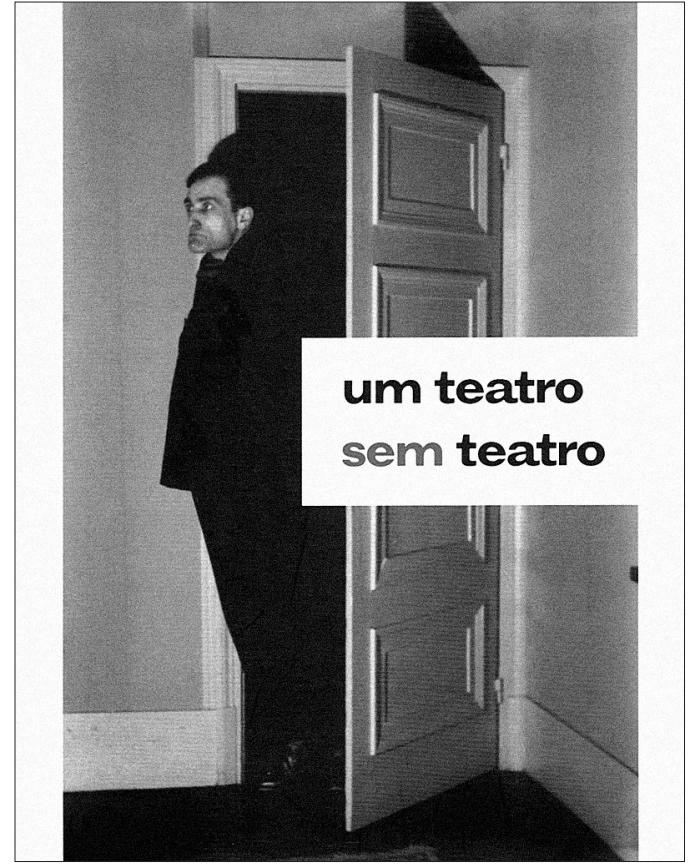

No âmbito da exposição Um teatro sem teatro, patente no Centro Cultural de Belém, foi publicado um belissimo catálogo, através do qual a podemos rememorar. É devido ao seu valor substantivo que ele nos merece um olhar crítico, pese embora o ano e meio que dista da mostra pública (Outubro de 2007 a Janeiro de 2008), na medida em que se constitui como um admirável objecto documental.

Produzida em conjunto pelo Museu d'Art Contemporani de Barcelona e pelo Museu Colecção Berardo, esta exposição teve por objectivo instigador compreender a influência do teatro e da teatralidade nas artes plásticas do século XX. Para isso, a viagem começa, necessariamente, com as vanguardas modernistas dos anos dez, terminando nos finais dos anos oitenta, colocando em relevo artistas e movimentos centrais da história do teatro, da dança e da performance nos anos 60/70, sobretudo, aqueles que, de forma inequivoca, desafiaram os limites do teatro tradicional com base no texto e na premissa do palco como ilusão. De um ponto de vista teórico, a iniciativa tem por âncora um dos textos matriciais da discussão contemporânea em torno da teatralidade na arte: o seminal artigo "Art and Objecthood", de Michael Fried (Artforum, 1967), onde o autor desenvolve uma visceral argumentação contra a nova arte minimalista, encontrando as razões da sua insuficiência no efeito teatral que ela comportava, obrigando a uma outra relação com o espaço e com o espectador. Seria apenas na presença e na relação de proximidade

\section{AA.VV.,Um teatro sem teatro, catálogo da exposição, Lisboa, Museu d'Art Contemporani de Barcelona e Museu Colecção Berardo, 2007.}

negociada com este último que a obra poderia ganhar sentido. Ela transformara-se, portanto, num acontecimento.

Sendo um modo de construir realidades (ilusórias), 0 teatro vai afirmar-se, a partir dos anos 60, e cada vez mais como um modo de construir planos de relação e participação do espectador na obra, recusando, no caso da performance, toda a noção de representação, de referente e de narratividade. Processos idênticos acontecem nas outras artes, facto a que não é alheia a génese hibrida da performance e a predominante diluição de fronteiras artísticas. Consequentemente, a teatralidade surge como um conceito operatório determinante para reflectir a complexidade crescente de categorias como o tempo, o espectador, o espectáculo, a presença e a efemeridade, no teatro e nas outras artes que nele encontram formas de escapar aos seus limites disciplinares.

Conforme sublinham os seus curadores, Bernard Blistène e Yann Chateigné, Um teatro sem teatro não é, contudo, uma exposição sobre teatro, nem pretende evocar historicamente os momentos marcantes das artes performativas; é antes uma exposição sobre "as diferentes formas de investigação que ele [o teatro] suscita" (p. 53), ou seja, o seu foco incide nas possibilidades de questionar a representação e a autoreflexividade que o modelo teatral oferece às artes visuais, analisando criticamente as suas prerrogativas (p. 54). Para alguém com uma formação teatral de base, ver o teatro através do olhar de outrém não poderia ser mais aliciante, embora em matérias de interdisciplinaridade, e sobretudo numa perspectiva teórica, haja cuidados preventivos essenciais para um bom resultado. A questão fulcral prende-se com a construção de um vocabulário partilhado, pois nem sempre as diferentes artes e saberes atribuem os mesmos sentidos aos mesmos conceitos. Logo, perguntamo-nos: de que teatro se fala aqui? Ou, como se define este "teatro sem teatro"?

Seguindo um critério cronológico (tal como a exposição), este catálogo reúne preciosas imagens de teatro, performance e artes visuais de todo o século XX, acompanhadas de pequenos textos documentais. Como é hábito, o extenso conjunto de imagens faz-se preceder de alguns textos de cariz teórico, dentre os quais se destacam duas entrevistas: uma conversa entre os filósofos Elie During e Alain Badiou, tendo o último já escrito obras relevantes sobre o teatro (no tocante à sua dimensão colectiva e pública) e cujo pensamento sobre o acontecimento inspira um diálogo elevado; e uma entrevista 
a Jean-Jacques Lebel, um dos primeiros criadores e pensadores de happenings na Europa, em que dá testemunho das descobertas dos anos 60 na primeira pessoa, facto não só inestimável, como também em vias de extinção (o "Pai" do happening, Allan Kaprow, morreu em 2006, ano em que se preparava a grande retrospectiva Allan Kaprow: Art as Life, na Haus der Kunst, Munique). Pena é que a altamente negligenciada tradução de outros textos, designadamente, no de maior vulto teórico ("Playground", de Patricia Falguières), dificulte em muito a leitura e até a compreensão do próprio discurso, empobrecendo-o. A fechar o volume, porém, um glossário não exaustivo (redigido por Marc Dachy) e uma cronologia mundial de importantes eventos nas artes performativas e plásticas entre 1988 e 1989 revelam-se oportunos e curiosos apêndices.

Sem sombra de dúvida, na laboriosa e deslumbrante pesquisa de imagens consiste a inédita mais-valia deste catálogo, pois disponibilizar esta documentação dispersa (e rara) reveste-se de uma pertinência e interesse fundamentais, tanto para o curioso quanto para o estudioso. Há, porém, dois aspectos menos coerentes na estruturação interna dos documentos e práticas artísticas, de que já a exposição padecia. Uma vez adoptado o critério cronológico e estabelecendo o claro propósito de compreender as influências do teatro no discurso das artes plásticas, não é evidente, por um lado, a opção de separar teatro e dança nessa aproximação, nem, por outro, a selecção de algumas referências teatrais em detrimento de outras. Sem o assinalar de forma argumentada, o catálogo (tal como a exposição) separa os documentos da dança dos do teatro, provocando um corte na linha de interpretação desenhada para o leitor a meio da viagem. Confuso, o leitor (e o visitante) é forçado a regressar aos anos vinte, quando já estava no final dos anos 70 , para refazer o mesmo caminho mas agora a partir do filão da dança. Por que razão separá-los quando, justamente, desde os anos 60 assistimos a uma intensa dissolução de fronteiras disciplinares e a uma profunda fertilização mútua dos vários campos artísticos? Para além de hoje em dia o conceito de teatro poder incluir todas as artes de palco (dai também o termo alternativo "artes performativas"), beneficiando de uma amplitude mais sintónica com as suas práticas actuais, esta escolha manifesta pouca agilidade na manipulação dos conceitos de uma forma eficaz e compreensivel para uma abordagem interdisciplinar. No que toca às referências teatrais convocadas, se são óbvios Alfred Jarry, Marinetti, os Dada Artaud, Grotowski, Kantor ou o Living Theatre, menos óbvios são alguns exemplos do panorama espanhol legitimamente colocados a par dos grandes nomes

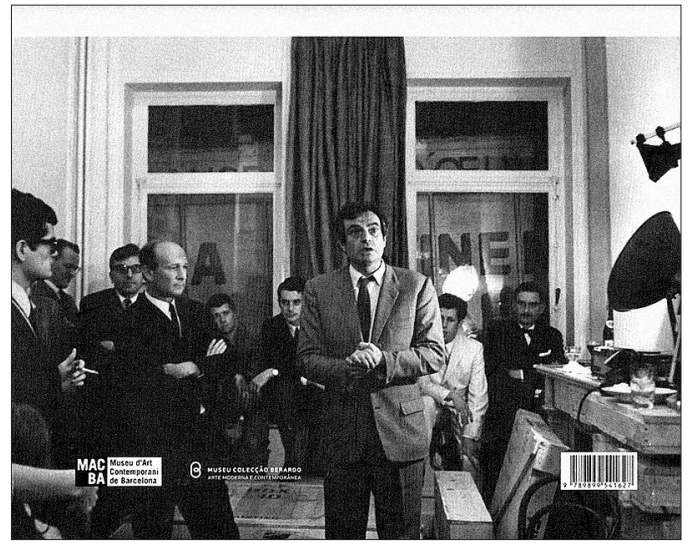

internacionais, mas em função dos quais se sente a falta dos pares portugueses. Para dar apenas um exemplo maior, por que não integra esta exposição co-produzida pelas instituições espanhola e portuguesa um nome como o de Almada Negreiros?

Claramente, o teatro para o qual nos remetem os curadores corresponde a uma metáfora mais do que a uma prática. Ela surge como modelo de eleição em diversos transportes interdisciplinares ao longo do pensamento do século $X X$, que recorrem ao conceito para operacionalizar um discurso estético, filosófico, em suma, reflexivo. É que o teatro encerra em si um mistério particular da representação na arte pois transforma o tempo, o espaço e os corpos vivos em alteridades simultaneamente próximas e intocáveis e, por isso, se torna tão sedutor à elaboração teórica. Não obstante válida e possível, esta opção cria apenas um problema quando se integraram e articularam expressamente as práticas teatrais e não somente o conceito abstracto que, aliás, usualmente remete para a matriz do teatro de texto e não para o paradigma da performance. Em virtude das revoluções impulsionadas por este novo paradigma, a própria noção de teatro vê-se radicalmente amplificada e dilui-se nas fronteiras disciplinares. Neste sentido, o que se torna verdadeiramente transversal a todos os campos artísticos será o conceito de teatralidade, ou seja, a perspectiva particular, o ângulo do olhar artístico através do qual um mundo pode ser criado (independentemente do seu grau de ficção), dando-se a ver e estabelecendo-se num plano determinado de relação com o outro. Embora enunciado de várias maneiras nos textos ensaísticos e introdutórios, esta dimensão da teatralidade não ganha espessura programática na organização conceptual do catálogo, que poderia ter optimizado largamente os seus esforços e inquietudes com a colaboração de um programador ou investigador da área especifica do teatro ou das artes performativas. 